\title{
Endoscopic endonasal surgery for massive subarachnoid neurocysticercosis: illustrative case
}

\author{
William W. Lines, MD, ${ }^{1}$ Juan Luis Gómez-Amador, MD, ${ }^{2}$ Hector H. García, MD, PhD, ${ }^{3,4}$ Jorge E. Medina, MD, ${ }^{1}$ Elías Lira, MD, ${ }^{1}$ \\ Luis A. Antonio, MD, ${ }^{1}$ Jose Calderon, MD, ${ }^{1}$ Jesús Félix, MD, ${ }^{1}$ Luis J. Saavedra, MD, ${ }^{1}$ Yelimer Caucha, MD, ${ }^{1}$ and \\ Carlos M. Vásquez, MD ${ }^{1}$

\begin{abstract}
${ }^{1}$ Department of Neurosurgery, Instituto Nacional de Ciencias Neurológicas, Lima, Perú; ${ }^{2}$ Department of Neurological Surgery Instituto Nacional de Neurología y Neurocirugía "Manuel Velasco Suárez," Mexico City, México; ${ }^{3}$ Cysticercosis Unit, Instituto Nacional de Ciencias Neurológicas, Lima, Perú; and ${ }^{4}$ Center for Global Health, Universidad Peruana Cayetano Heredia, Lima, Perú
\end{abstract}

BACKGROUND Subarachnoid neurocysticercosis (NCC) is associated with high morbidity and mortality rates. Conventional transcranial approaches and transventricular endoscopy have been previously reported for extraparenchymal NCC and ventricular NCC, respectively. By October 2019, endonasal endoscopic approaches had not been used for the treatment of NCC.

OBSERVATIONS A 54-year-old-woman with NCC was admitted with acute neurological deterioration due to severe intracranial hypertension caused by massive subarachnoid NCC cysts, as evidenced on magnetic resonance imaging (MRI) with great brainstem compression. The case was discussed, and an endoscopic endonasal resection of the NCC cysts was scheduled. The diagnosis was confirmed by pathological anatomy. There were no complications in the surgery, with marked neurological improvement. Control MRIs demonstrated a significant reduction of NCC cysts.

LESSONS Minimally invasive approaches are an excellent alternative for skull-base tumoral and infectious pathology. Prior knowledge of the pathophysiology and the authors' experience in the management of patients with NCC allowed them to propose this approach, with optimal results.

https://thejns.org/doi/abs/10.3171/CASE21366

KEYWORDS endoscopic endonasal; massive neurocysticercosis; subarachnoid neurocysticercosis; intracranial hypertension

Neurocysticercosis (NCC) is the infection of the central nervous system (CNS) by the larval stage of Taenia solium. NCC is a public health problem that affects about 50 million people worldwide and is endemic in Latin America, Africa, and the Indian subcontinent. ${ }^{1-3}$ The management of NCC requires multidisciplinary and multimodal treatment, including surgical approaches. Depending on its location, there are three main types of disease: parenchymal, ventricular, and subarachnoid. Subarachnoid NCC (mainly involving the basal and Sylvian cisterns) is associated with high morbidity and mortality rates, secondary to hydrocephalus and/or strokes due to mechanisms not yet well determined. ${ }^{4}$ Extraparenchymal NCC is currently treated with conventional transcranial approaches or transventricular endoscopic approaches, with subsequent medical treatment with albendazole and steroids. ${ }^{5-7}$
We present a case of massive NCC in basal cisterns treated by an endonasal endoscopic approach.

\section{Illustrative Case}

A 54-year-old female with a 7-year medical record of hydrocephalus treated with a ventriculoperitoneal shunt presented to the National Institute of Neurological Sciences in Lima, Peru. Over the past 7 months, she had experienced moderate to severe headache, confusion, progressive disorientation, postural instability, and ataxia. Two weeks before admission, she complained of swallowing difficulty. Immunodiagnosis using enzyme-linked immunoelectrotransfer blot, Western blot (sensitivity of $98 \%$ and specificity of $100 \%$ in patients with two or more viable brain lesions) was reactive to all seven diagnostic antibody bands. Magnetic resonance imaging (MRI),

ABBREVIATIONS CNS = central nervous system; FIESTA = fast imaging employing steady-state; MRI = magnetic resonance imaging; NCC = neurocysticercosis INCLUDE WHEN CITING Published September 6, 2021; DOI: 10.3171/CASE21366.

SUBMITTED June 18, 2021. ACCEPTED July 19, 2021.

(C) 2021 The authors, CC BY-NC-ND 4.0 (http://creativecommons.org/licenses/by-nc-nd/4.0/). 

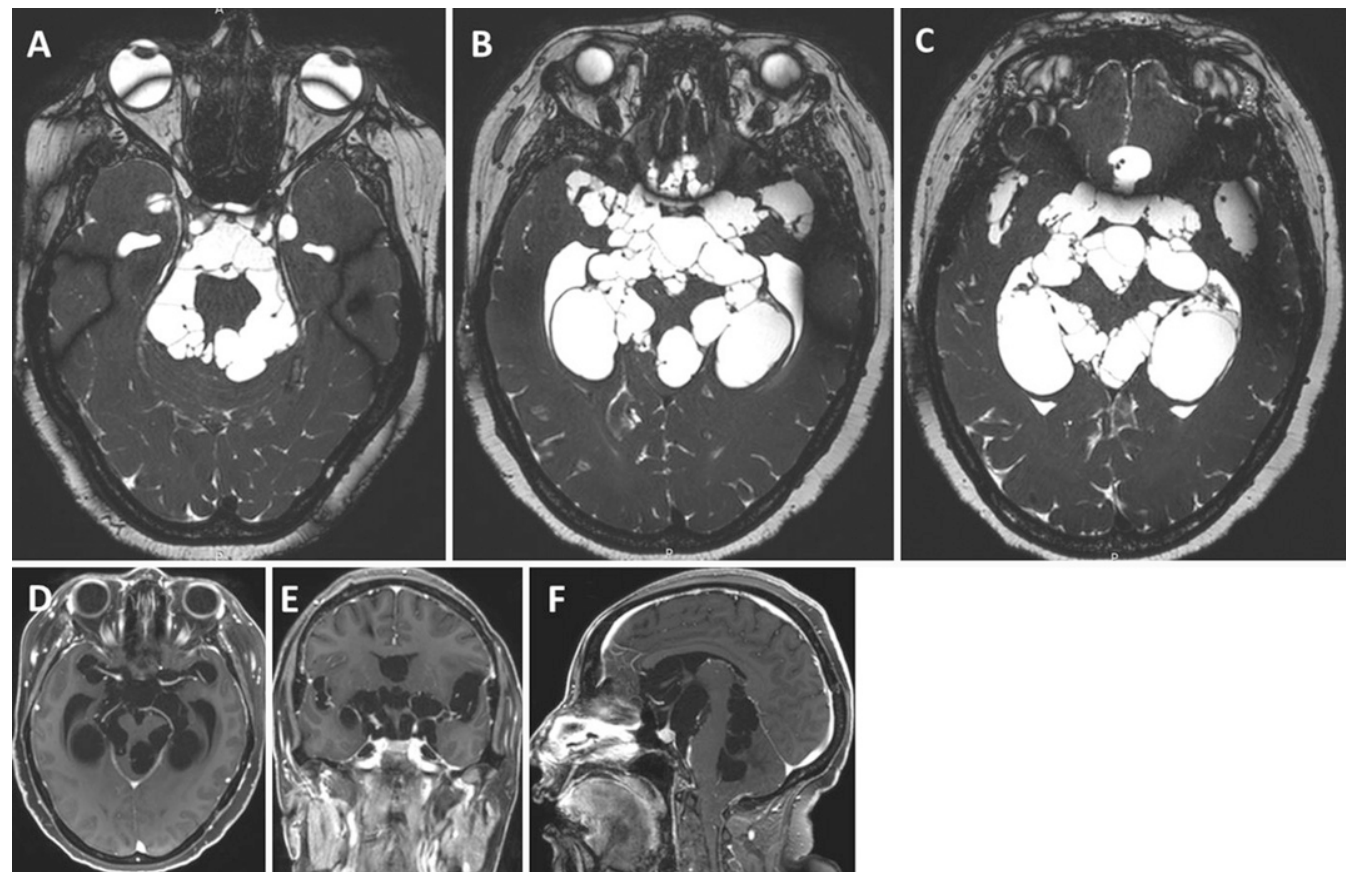

FIG. 1. A-C: Axial FIESTA-weighted MRI demonstrating multiple confluent cystic lesions in the basal cisterns and sylvian fissures, which compress and deform the brainstem. D-F: Sagittal, coronal, and axial T1-weighted postgadolinium MRI showing cerebral arteries surrounded by cysts and elongated pituitary infundibulum.

particularly that using fast imaging employing steady-state (FIESTA) sequence, showed very large cyst conglomerates in basal and Sylvian cisterns, affecting and compressing the brainstem (Fig. 1). T1sequence MRI demonstrated an elongated pituitary infundibulum offering enough room for a parainfundibular approach. The case was discussed, and an endoscopic endonasal exploration was considered due to the nature of the disease and the possible benefit to the patient, with minimal risk of complications, using a natural corridor, avoiding manipulation of the brain parenchyma, as well as the blood vessels and cranial nerves compromised in the region.

\section{Operation}

We used a STORZ equipment and rigid endoscope $\left(0^{\circ}, 18 \mathrm{~cm} \times\right.$ $4 \mathrm{~mm}$ ) for an extended endoscopic endonasal approach to the sellar tubercle. First, we accessed through the right nostril to prepare the right nasoseptal flap. A left reverse nasoseptal flap was also used to protect the cartilage of the exposed nasal septum. Once the rostrum was removed, the sellar floor, anterior wall, and sellar tubercle were drilled. Finally, we opened the dura in a "Y," taking care of the hemostasis of the intercavernous sinus. The pituitary gland and the infundibulum were identified; the left parainfundibular corridor was approached since it allowed for an easier dissection. The cysts were exposed and retrieved using gentle suction. Some of the cysts were removed by slight traction using forceps; most cysts were evacuated continuous irrigation with saline and suction (Fig. 2). We finished the procedure when no cysts were seen in the interpeduncular cistern. The procedure was performed without complications, facilitated by the lack of cyst adherence to the surrounding tissues. The reconstruction was performed in three planes, with dura substitute, bone gasket, nasoseptal flap, and fibrin sealant. There was no need of lumbar drainage since the patient had the ventriculoperitoneal shunt, and a multilayer gasket seal technique was used.

\section{Postoperative Course}

There were no postoperative complications, and neurological examination 1 week after surgery demonstrated significant improvement of confusion, disorientation, and swallowing. Pathology confirmed the diagnosis (Fig. 3). Figure 4 shows the postsurgical MRI, demonstrating a significant reduction of cyst burden. Six weeks after surgery, the patient was treated with albendazole and dexamethasone (albendazole $400 \mathrm{mg} / \mathrm{day}$ for 30 days, with concomitant dexamethasone at $8 \mathrm{mg} / \mathrm{day}$ for 2 weeks and then gradually withdrawn over 6 weeks) for residual subarachnoid neurocysticercosis. At a 2-month follow-up visit, her neurological examination was normal, with mild intermittent headache as her only complain.

\section{Discussion}

\section{Observations}

To the best of our knowledge, there are no previous reports of endonasal endoscopic approaches for basal cistern NCC cysts. Endonasal endoscopic approaches are minimally invasive and are designed for treating tumors and vascular and infectious skull-base pathologies. This approach allows direct access to pathologies in the midline of the skull base, with minimal manipulation of neurovascular structures and almost no manipulation of healthy brain tissue. In 2005, Kassam A. et al. introduced the endoscopic classification of the skull base taking as reference the sphenoid sinus, through which it is possible to get from the anterior cranial fossa to the second cervical vertebra in the sagittal plane. . $^{-12}$

Subarachnoid NCC can occur with hydrocephalus, stroke, or focal neurological symptoms. ${ }^{6,13}$ Symptoms associated with subarachnoid 

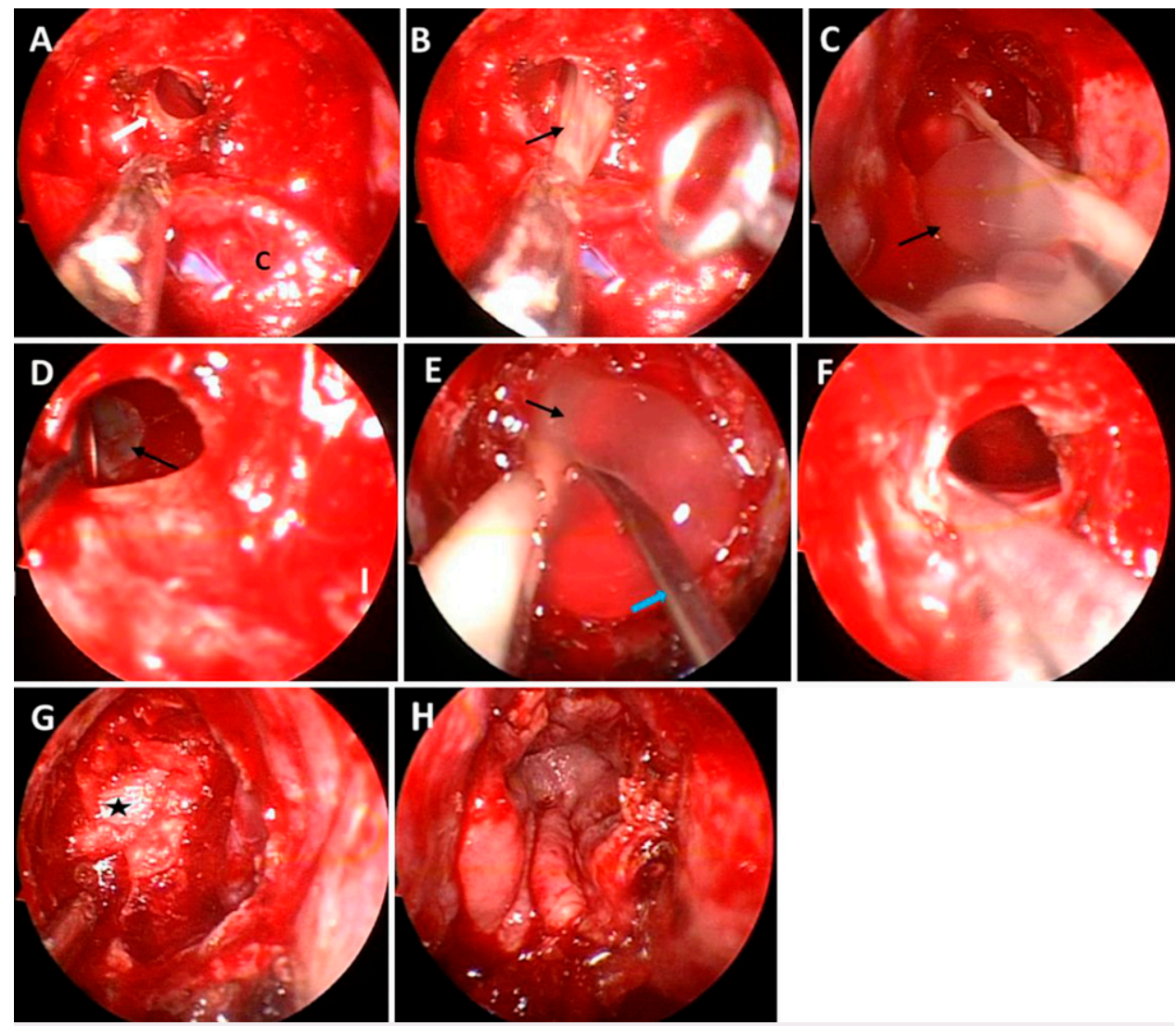

FIG. 2. Intraoperative images. A: Initial view after drilling the floor and sellar tubercle, a pituitary infundibulum (white arrow) and pituitary gland are seen in the lower part. $\mathrm{C}=$ cottonoid. B: Removal of cysts (black arrow in B, C, D and E) by direct traction. C: Cyst removal by direct traction. D: NCC cysts in the interpeduncular cistern. E: Cyst removal by saline irrigation with a cannula (blue arrow). F: Complete removal of premesencephalic cistern cysts. G: Reconstruction with a dura mater substitute and bone gasket (black star). H: Placement of the nasoseptal flap fixed with fibrin glue.

cysts are due to severe inflammatory reaction of blood vessels in the subarachnoid spaces that can cause brain stem infarctions, basal nuclei, and the mass effect with increased intracranial pressure, which is one of the causes of higher mortality in these patients. ${ }^{14}$ Different types of neurosurgical approaches are used: the traditional ones (pterional, frontotemporal, suboccipital, etc.), as well as the stereotactic, transventricular endoscopic approaches. All of them aim to solve the mass effect of parasites at different locations. ${ }^{15-18}$ In the extraparenchymal racemose form, where cerebral spinal fluid flow obstruction may occur by different mechanisms at some point, patients can manifest severe intracranial hypertension secondary to both hydrocephalus and the effect of the cysts' own mass. ${ }^{19}$

Giant or multiple cysts in the basal subarachnoid spaces (suprasellar cistern or basal cisterns) may generate a compressive effect on the surrounding structures. ${ }^{20}$ Craniotomy with cyst removal leads to a good outcome in the majority of cases. Although standard microsurgical procedures, consisting of transcranial approaches, have long been used to remove intraventricular cysts, ${ }^{21-23}$ the current standard surgical procedure for removing ventricular cysts (lateral and third ventricle) is the minimally invasive endoscopic approach. ${ }^{24,25}$ Endoscopic surgery prevents complications of a large craniotomy and reduces the manipulation of healthy brain tissue. A rigid endoscope can be used for excision of lateral and third ventricular cysts. Flexible endoscopes are best suited for cysts of the third ventricle and the aqueduct. In most cases, saline irrigation is enough for the resection of cysts since they do not adhere to neurovascular structures. In some cases, cysts adhere tightly to the surrounding neurovascular structures and may not easily "deliver." For those unusual cases, a broader conventional approach should be used. ${ }^{21,24}$

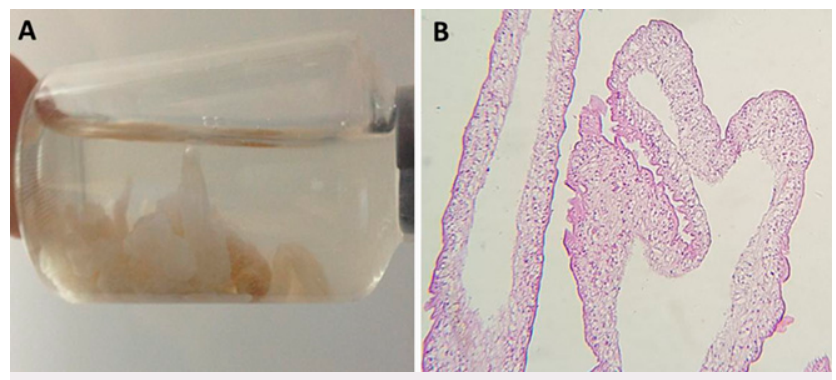

FIG. 3. Cysticercal membranes extracted by surgery. A: Membranes of cysts. B: Typical double-layer, eosinophilic membranes. Hematoxylin/eosin. Original magnification $\times 10$. 

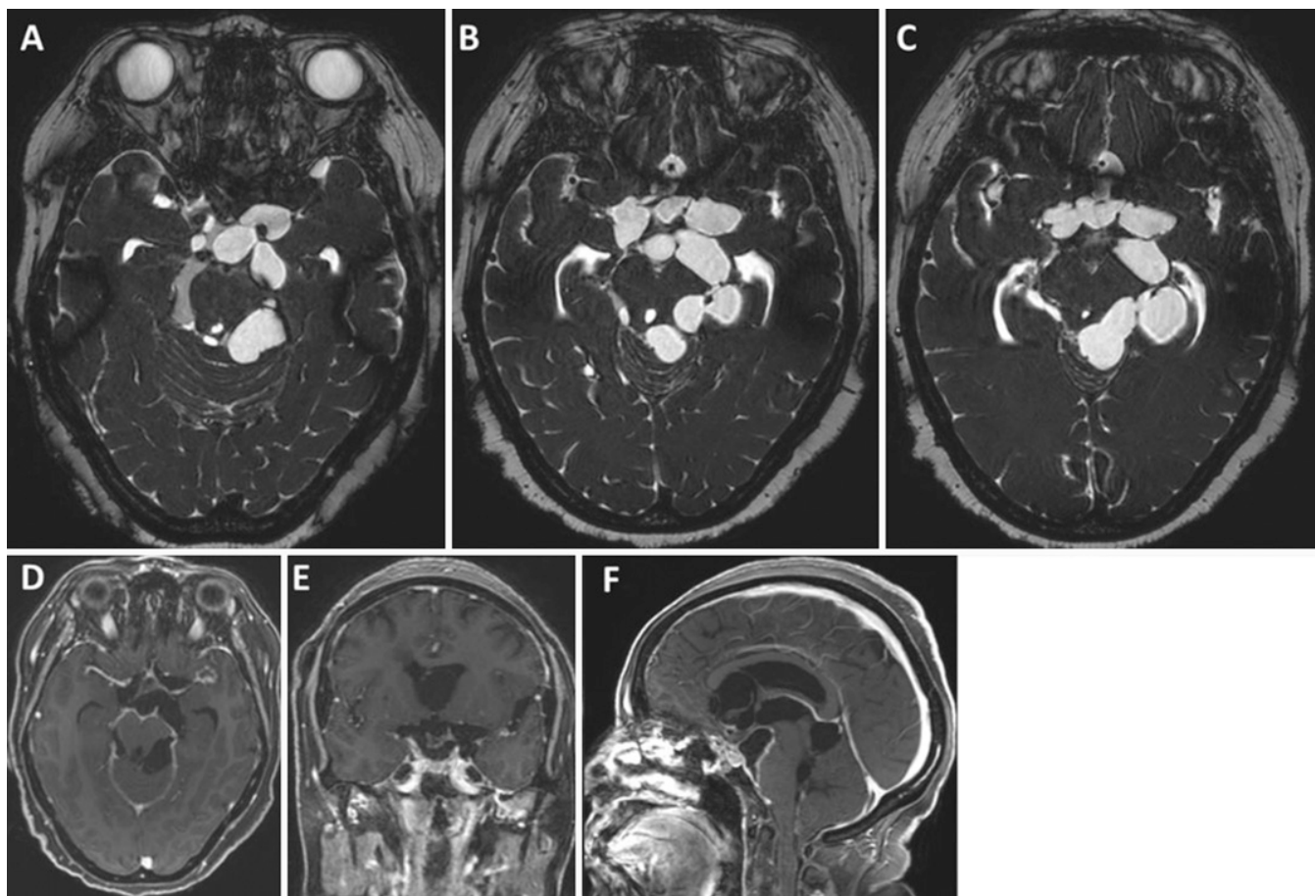

FIG. 4. A-C: Postoperative axial FIESTA-weighted MRI showing a great decrease in cystic lesions in basal cisterns and Silvio fissures and a decrease in compression and deformation of the brainstem. D-F: Sagittal, coronal, and axial T1-weighted postgadolinium MRI showing cyst-free brain arteries and normal pituitary infundibulum, obtained 2 months after surgery.

Careful neuroimaging analysis provides the best guidance on the appropriate approach for each case. In our case, the anatomy of the sphenoid sinus and the location of the cysts allowed us to perform the endonasal endoscopic approach.

We aimed to decompress neural structures (brainstem, pituitary stalk, hypothalamus) by removing multiple cysts that caused the compression to these structures. This was successfully obtained, as demonstrated by the good clinical evolution of the patient and postoperative MRI. The premesencephalic cisterns are difficult to reach using the conventional dorsolateral approaches, in particular in NCC, where arachnoid fibrosis may be present. The crural, ambiens, and quadrigeminal cisterns are too posterior to be explored with this approach. Cysts from these spaces were extracted using profuse saline irrigation. While a pterional approach could have allowed the remotion of more parasitic material, we decided on a less-invasive approach, considering the deteriorated condition of the patient. The endoscopic endonasal transtubercular approach was used to reach this complex region directly, without compromising the associated vascular and neural structures, achieving an early exposition of the pituitary gland and the infundibulum, identifying and removing the multiple cysts, and allowing adequate decompression. There is no risk of adverse reactions with the rupture of the NCC cysts. Most of the surgeons reporting these procedures do not describe any incidents associated with the intraoperative rupture of cysts. ${ }^{24,26}$

\section{Lessons}

NCC cysts are usually free in the subarachnoid space without significant adherences to neurovascular structures, and their exeresis can be easily achieved with gentle traction and/or continuous saline irrigation. Intracranial pressure itself contributes to their externalization.
The suprasellar and premesencephalic cisterns are a well-defined compartment located between the pituitary gland and the inferior surface of the optic nerves and chiasm; its lateral limit is delineated by the junction of the arachnoid membranes of the carotid and the lateral recess of the interpeduncular cistern. This space contains the dorsal pituitary surface, the sellar diaphragm, the infundibulum, the inferior surface of the optic nerves and chiasm, as well as the superior hypophyseal arteries. Exploration of this particular compartment is difficult using a dorsolateral approach.

We applied an extended endonasal endoscopic approach as a better alternative to conventional approaches for the management of midline skull-base pathologies, particularly those that are tumoral or infectious, such in this case, and avoiding the manipulation of normal vascular and neural structures.

\section{References}

1. Del Brutto OH, Garcia HH. Neurocysticercosis. Handb Clin Neurol. 2013;114:313-325.

2. Fabiani S, Bruschi F. Neurocysticercosis in Europe: still a public health concern not only for imported cases. Acta Trop. 2013;128(1):18-26.

3. Zammarchi L, Strohmeyer M, Bartalesi F, et al. Epidemiology and management of cysticercosis and Taenia solium taeniasis in Europe, systematic review 1990-2011. PLoS One. 2013;8(7):e69537.

4. Coyle CM, Mahanty S, Zunt JR, et al. Neurocysticercosis: neglected but not forgotten. PLoS Negl Trop Dis. 2012;6(5):e1500.

5. DeGiorgio CM, Houston I, Oviedo S, Sorvillo F. Deaths associated with cysticercosis. Report of three cases and review of the literature. Neurosurg Focus. 2002;12(6):e2. 
6. Fleury A, Carrillo-Mezo R, Flisser A, Sciutto E, Corona T. Subarachnoid basal neurocysticercosis: a focus on the most severe form of the disease. Expert Rev Anti Infect Ther. 2011;9(1):123-133.

7. Bhattarai $\mathrm{R}$, Budke $\mathrm{CM}$, Carabin $\mathrm{H}$, et al. Estimating the non-monetary burden of neurocysticercosis in Mexico. PLoS Negl Trop Dis. 2012;6(2):e1521.

8. Kassam AB, Gardner P, Snyderman C, Mintz A, Carrau R. Expanded endonasal approach: fully endoscopic, completely transnasal approach to the middle third of the clivus, petrous bone, middle cranial fossa, and infratemporal fossa. Neurosurg Focus. 2005;19(1):E6.

9. Kassam A, Snyderman CH, Mintz A, Gardner P, Carrau RL. Expanded endonasal approach: the rostrocaudal axis. Part I. Crista galli to the sella turcica. Neurosurg Focus. 2005;19(1):E3.

10. Kassam A, Snyderman CH, Mintz A, Gardner P, Carrau RL. Expanded endonasal approach: the rostrocaudal axis. Part II. Posterior clinoids to the foramen magnum. Neurosurg Focus. 2005;19(1):E4.

11. Paluzzi A, Gardner P, Fernandez-Miranda JC, Snyderman C. The expanding role of endoscopic skull base surgery. $\mathrm{Br} \mathrm{J}$ Neurosurg. 2012;26(5):649-661.

12. Kassam AB, Snyderman C, Gardner P, Carrau R, Spiro R. The expanded endonasal approach: a fully endoscopic transnasal approach and resection of the odontoid process: technical case report. Neurosurgery. 2005;57(1 Suppl):E213.

13. Proaño JV, Madrazo I, Avelar F, López-Félix B, Díaz G, Grijalva I. Medical treatment for neurocysticercosis characterized by giant subarachnoid cysts. N Engl J Med. 2001;345(12):879-885.

14. Rajshekhar V. Surgical management of neurocysticercosis. Int $\mathrm{J}$ Surg. 2010;8(2):100-104.

15. Khade P, Lemos RS, Toussaint LG. What is the utility of postoperative antihelminthic therapy after resection for intraventricular neurocysticercosis? World Neurosurg. 2013;79(3-4):558-567.

16. Rangel-Castilla L, Serpa JA, Gopinath SP, Graviss EA, DiazMarchan P, White AC Jr. Contemporary neurosurgical approaches to neurocysticercosis. Am J Trop Med Hyg. 2009;80(3):373-378.

17. Gonzales I, Garcia HH. Current status and future perspectives on the medical treatment of neurocysticercosis. Pathog Glob Health. 2012;106(5):305-309.

18. Bruno E, Bartoloni A, Zammarchi L, et al. Epilepsy and neurocysticercosis in Latin America: a systematic review and meta-analysis. PLoS Negl Trop Dis. 2013;7(10):e2480.
19. Garcia HH, Gonzalez AE, Gilman RH. Cysticercosis of the central nervous system: how should it be managed? Curr Opin Infect Dis. 2011;24(5):423-427.

20. Bannur U, Rajshekhar V. Cisternal cysticercosis: a diagnostic problem-a short report. Neurol India. 2001;49(2):206-208.

21. Apuzzo ML, Dobkin WR, Zee CS, Chan JC, Giannotta SL, Weiss $\mathrm{MH}$. Surgical considerations in treatment of intraventricular cysticercosis. An analysis of 45 cases. J Neurosurg. 1984;60(2):400-407.

22. Lobato RD, Lamas E, Portillo JM, et al. Hydrocephalus in cerebral cysticercosis. Pathogenic and therapeutic considerations. J Neurosurg. 1981;55(5):786-793.

23. Loyo M, Kleriga E, Estañol B. Fourth ventricular cysticercosis. Neurosurgery. 1980;7(5):456-458.

24. Bergsneider M, Holly LT, Lee JH, King WA, Frazee JG. Endoscopic management of cysticercal cysts within the lateral and third ventricles. J Neurosurg. 2000;92(1):14-23.

25. Bergsneider M. Endoscopic removal of cysticercal cysts within the fourth ventricle. Technical note. J Neurosurg. 1999;91(2):340-345.

26. Stern WE. Neurosurgical considerations of cysticercosis of the central nervous system. J Neurosurg. 1981;55(3):382-389.

\section{Disclosures}

The authors report no conflict of interest concerning the materials or methods used in this study or the findings specified in this paper.

\section{Author Contributions}

Conception and design: Lines, Gómez-Amador, Vásquez. Acquisition of data: Lines, Félix, Caucha. Analysis and interpretation of data: Lines, García, Medina. Drafting the article: Lines, Gómez-Amador, García. Critically revising the article: Lines, García, Saavedra. Reviewed submitted version of manuscript: Lines, Gómez-Amador, García, Antonio. Approved the final version of the manuscript on behalf of all authors: Lines. Administrative/technical/material support: Lines, Calderon. Study supervision: Lines, Lira. Operating surgeon: Lines.

\section{Correspondence}

William W. Lines: Instituto Nacional De Ciencias Neurológicas, Lima, Peru.williamincn@hotmail.com. 